\title{
Bergsonin paluu
}

\author{
JUHO HOTANEN, VIERAILEVA PÄ̈̈TOIMITTAJA
}

Henri Bergson (1859-1941) oli 1900-luvun alun tähtifilosofi, joka palkittiin filosofisesta työstään kirjallisuuden Nobel-palkinnolla 1927, kirjoittamatta koskaan kaunokirjallisuutta. Seuraava filosofisukupolvi suhtautui erittäin kriittisesti hänen filosofiaansa (ks. esim. Arouet 1929; Nizan 2002; Sartre 2007). Myös debatti Albert Einsteinin kanssa heikensi Bergsonin arvostusta tieteen kentällä, vaikka Bergson itse pyrki selventämään, että koko debatti perustui Einsteinin väärinkäsitykseen hänen filosofiansa suhteen (ks. Merleau-Ponty 1960, 246-248; Canales 2005). Bergsonin ajattelu nähtiin vanhanaikaisena ja poliittisesti konservatiivisena. Ehkä siksi on myös jollain tavalla yllättävää, että Gilles Deleuze nosti Bergsonin mukaan radikaaliin filosofiseen ajatteluun 1960-luvulla (Deleuze 1993; Deleuze 2018). Samaan aikaan Bergsonista tehtiin skolaaria tutkimusta Les études bergsoniennes -julkaisussa. Vaikka monet ranskalaiset fenomenologit, kuten Emmanuel Levinas, Maurice Merleau-Ponty ja Paul Ricœur, tunnustivat Bergsonin merkittävyyden (ks. esim. Lawlor 2003; Kelly 2010), hänen filosofiaansa leimasi pitkään tietynlainen epämuodikkuus ja poissaolo.

2000-luvulla kiinnostus Bergsonin filosofiaan on ollut nousussa. Ranskassa erityisesti Annales bergsoniennes -julkaisu on jatkanut Bergson-tut- kimusta. Kuitenkin vasta 2010-luvulla, lähes sata vuotta alkuperäisen Bergson-buumin hiipumisen jälkeen, kiinnostus hänen ajatteluaan kohtaan on herännyt uudestaan paljon laajemmin. Bergsonin filosofiassa on aineksia, jotka sopivat useisiin nykyfilosofian keskeisiin keskusteluihin, esimerkiksi suhteessa postkolonialismiin ja dekolonisaatioon (Diagne 2011; Pitts \& Westmoreland 2019), uuteen materialismiin ja feminismiin (Grosz 2017) sekä kapitalismikritiikkiin ja elokuvatutkimukseen (Lazzarato 2019).

Kärjistäen voisi sanoa, että joko Bergsonin filosofia kuuluu menneeseen ajattelutapaan, johon ei ole muuta syytä palata kuin aatehistoriallinen, tai sitten hänen filosofiansa on yhä elinvoimaista ja jotain mistä nykyinen ajattelu voi ammentaa uutta. Miksi Bergson syrjäytettiin 1900-luvun filosofian valtavirrasta niin nopeasti? Miksi hänen filosofiansa on tehnyt hidasta paluuta, joka on vihdoin tullut laajemman yleisön tietoisuuteen 2010- ja 2020-luvuilla? Mitä nykyfilosofit hakevat Bergsonilta?

Yksi mahdollinen vastaus näihin kysymyksiin liittyy fenomenologisen filosofian ja erityisesti Martin Heideggerin ajattelun hallitsevaan asemaan 1900-luvun mannermaisessa filosofiassa. Sekä Bergsonin että Heideggerin keskeinen 
teema on ajallisuus. Heidegger julkaisi Olemisen ja ajan samana vuonna kuin Bergsonille myönnettiin Nobel-palkinto. Heidegger esittää teoksessaan yksityiskohdattoman, mutta tyrmäävän kritiikin Bergsonin aikakäsityksestä (Heidegger 2000, 508 viite 378). Uusimmassa tutkimuksessa tätä kritiikkiä on kuitenkin kyseenalaistettu ja on väitetty, että Heidegger näyttää päinvastoin saavan oleellisia vaikutteita Bergsonin aikakäsityksestä, toki sitä myös muuntaen: Heidegger seuraa Bergsonia erottelussa yhtäältä laskennallisen ja sulkeutuvan ajan ja toisaalta koetun ja avautuvan ajallisuuden välillä (Riquier 2009; Massey 2015). Heideggerin kritiikki antaa Bergsonin aikakäsityksestä staattisen kuvan, ja kuten Levinas kirjoittaa, jättää täysin huomiotta Bergsonin kuvaileman ajallisen muutoksen ja transitiivisuuden, joka nimenomaan on myös Heideggerin aikakäsityksen ytimessä (Levinas 1967, 100).

Levinas ei kuitenkaan palauta Bergsonin ja Heideggerin filosofioita toisiinsa. Päinvastoin, hänen mukaansa niiden välillä on "radikaali ero" (Levinas 1996, 41). Tämän eron paikantaminen ei kuitenkaan ole helppo tehtävä. Selvää on, että Bergson ei korosta kuoleman ja ei-minkään merkitystä ajan ja olemisen suhteen vaan näkee nämä käsitteet pseudo-ongelmina (Levinas 2010, 38). Mutta on myös selvää, että Bergsonille ajallisuus ei muodosta mitään "omimpia mahdollisuuksia" eikä "kohtaloa" vaan on päinvastoin jatkuvaa, ennennäkemätöntä muutosta ja kehittymistä (progrès) (vrt. Heidegger 2000, 456-458).

Deleuze julisti "paluuta Bergsoniin", koska hänen mukaansa Bergsonin ajattelusta löytyi merkittäviä ideoita, joita nykyfilosofian olisi mahdollista hyödyntää (Deleuze 2003, 313). Nyt voidaan kenties puhua jo "Bergsonin paluusta", jossa Bergsonin filosofian merkitystä ja mahdollisuutta uudelleenarvioidaan sellaisenaan. Bergsonin uudelleenlukemisen kautta herää ensinnäkin merkittävä filosofianhistoriallinen kysymys, omiko 1900-luvun mannermaisen filosofian valtavirta sittenkin joitain Bergsonin ajattelun oleellisimpia juonteita, näennäisestä vastustuksestaan huolimatta. Toiseksi herää kysymys, avautuuko Bergsonin kautta jollain tavalla toisenlainen filosofia, sekä metodologisesti että sisällöllisesti, kuin erityisesti fenomenologinen filosofia.

Jos alamme lukea Bergsonin teoksia liian suurin odotuksin, saatamme pettyä. Bergsonin filosofia pohjautuu ranskalaiselle kartesiolaiselle traditiolle: keskiössä on ajatus välittömästä sisäisestä suhteesta itseen ja tämän henkisen ulottuvuuden ero materiaaliseen, ulottuvaiseen ja mitattavaan tasoon. Mutta onko Bergsonin filosofia todella niin kiinni välittömässä itsesuhteessa kuin aluksi saattaa vaikuttaa? Eikö hänen ajattelussaan sittenkin ole aineksia, jotka rikkovat tämän klassisen asetelman? Eivätkö Bergsonin kaikkein keskeisimmät teemat - ajallisuus, liike ja muutos - asetu vastoin välittömyyden oletusta, jonka rinnalle tulevat tavoittamattomuuden ja eriytymisen teemat? Erityisesti Merleau-Ponty ja Deleuze tuovat Bergson-tulkinnoissaan esiin juuri eriytymisen ja tietyn tavoittamattomuuden. Kummankaan tulkinnassa Bergsonin filosofian ydin ei palaudu perinteiseen käsitykseen välittömästä yhteensattumisesta, oli kyse sitten ajallisuudesta, olemisesta, perustasta tai itsestä. Nykyfilosofian kannalta nämä tulkinnat ovat merkittäviä (ks. esim. Lawlor 1998; Wambacq 2011; Olkowski 2021).

Bergsonin väitöskirjan Essai sur les données immédiates de la conscience (suom. Tutkielma tietoisuuden välittömästä sisällöstä, 1889) pääaiheena on vapaus, mutta suurimmaksi osaksi teos käsittelee sisäisen eli henkisen näkökulman eroa ulkoisesta, materiaalisesta todellisuudesta. Voidaan silti väittää, että Bergsonin tavoite ei ole niinkään erottaa henkeä ja materiaa toisistaan, kuten perinteisessä metafysiikassa, vaan näyttää se, miten henkinen osa meissä pakenee analyysin ja määrittelyn pyrkimyksiltä, sillä henkinen tai psyykkinen elämä on jatkuvassa muutoksen tilassa (Bergson 1982/1889, 150). Juuri tämä pakeneva osa on se, mistä vapaus tulee ja juuri siksi tilallistava ja homogenisoiva ajattelu ei koskaan voi tavoittaa vapauden ideaa (mt., 165, 173-174).

Bergson jatkaa toisessa, Matière et mémoire -teoksessaan (suom. Materia ja muisti, 1896) tämän tavoittamattoman ajattelemista ja syventää sitä huomattavasti. Eräs teoksen tärkeimmistä tehtävistä on kuitenkin edelleen osoittaa, ettei- 
vät materiaalinen todellisuus ja sitä analysoiva tieteellinen äly pysty tavoittamaan oleellisinta ihmisen olemassaolosta. Jos puhtaat muistot olisivat aivoissa säilössä, ne voisivat tuhoutua aivojen vaurioituessa tai kuollessa. Mutta koska muistot eivät ole tilassa vaan ajassa, ne eivät voi kadota jonkin materiaalisen olion tuhoutuessa (Bergson 1999/1896, 83). Muistot ovat henkisessä ulottuvuudessa. Mikään ei saa menneisyyttä tekemättömäksi - tai kuten Descartes kirjoitti: edes Jumala ei saa sitä tekemättömäksi, että olen ollut (Descartes 2002, 46). Menneisyys on siis pysyvästi olemassa (Bergson 1999/1896, 166). Vaikka menneisyys on väistynyt nykyisyydestä, eikä ole läsnä tilallisesti, se on kuitenkin aina läsnä ajallisessa mielessä.

Ajallinen läsnäolo ei kuitenkaan ole puhdasta läsnäoloa ilman poissaoloa, ja menneisyys tavoitetaan vain jännitteessä nykyisyyden materiaalisen tiheyden kanssa (mt., 187). Menneisyyttä ei tavoiteta sellaisenaan, vaan kyse on aina nykyisyyden kautta tapahtuvasta muistamisesta, jossa menneisyyden peräkkäisyys on pikemminkin päällekkäisyyttä ja lomittaisuutta kuin erillisiä muistoja. Tiedostamattomat muistot tulevat esiin ruumiillisina eli suhteessa nykyisyydessä tapahtuviin tekoihin ja havaintoihin. Kyse on kaksoisliikkeestä jatkuvuuden ja muutoksen välillä, intensiteetistä, joka syntyy tottumuksen ja puhtaan muistamisen risteyskohdassa. (Mt., 169.) Muistaminen tai mieleenpalauttaminen on toistoa, jossa jokainen toisinto on aina erilainen, ei vain määrällisesti vaan ennen kaikkea laadullisesti. Bergsonin mukaan kaikki sekä muuttuu että pysyy: tätä on muuttuva jatkuvuus (mt., 221). Näin ollen Bergson näyttää, että filosofian kannalta oleellisinta ei ole dualismi puhtaan havainnon ja puhtaan muistin välillä vaan se konkreettinen tai todellinen muutoksen liike, jota aina elämme (mt., 275).

L'évolution créatrice -teoksessaan (suom. Luova evoluutio, 1907) Bergson jatkaa aikaisempien teostensa ajatusta tietynlaisesta perustavanlaatuisesta tavoittamattomasta: elämä on jotain mikä pakenee inhimillisen älyn otteesta, eikä mahdu sen asettamiin malleihin. Kuitenkin se, mitä olen kutsunut tässä "tavoittamattomaksi”, on Bergso- nille nimenomaan sitä, minkä filosofia tavoittaa intuition metodilla välittömänä ja ei-älyllisenä yhteensattumisena. Kyse on tavoittamattomasta tieteelliselle ja matemaattiselle älylle, mutta ei filosofiselle ponnistukselle, sen yhtyessä ajalliseen muutoksen virtaukseen, joka antaa myös älylliselle ajattelulle sysäyksen.

Mutta mitä lopulta on tämä filosofinen ponnistus konkreettisessa mielessä? Eikö kyse ole jälleen risteämästä kahden liikkeen välillä? Miten muutoksen kanssa voisi olla välitön yhteensattuminen? Olemalla muutosta, olemalla muutos itse. Mutta jos muutos on todellista muutosta - ei ainoastaan junanvaunussa muuttuvaa maisemaa tarkkaileva matkustaja vaan itse muuttuva - välittömyys lipsahtaa aina tavoittamattomiin.

Bergsonin mukaan ylittääkseen puhtaan ymmärryksen ja sukeltaakseen elämän syvyyksiin filosofian on hypättävä (Bergson 1991/1907, 194). Tämä johtuu siitä, että filosofia ei voi edetä analysoivan ymmärryksen kautta intuitioon vaan ainoastaan intuitiosta ymmärrykseen. Filosofinen intuitio on pakenevaa ja epätäydellistä (mt., 239). Elämän sysäys (élan vital) ${ }^{1}$ ei tarjoa tietoisuudelle täydellistä yhtymistä ymmärryksen tuolla puolen sykkivään luontoon vaan ennen kaikkea elävyytensä ja luovuutensa. Filosofiassa ei siis ole kyse vain yhteensattumisesta vaan aina samalla myös etääntymisestä ja eriytymisestä, toisin sanoen keksimisestä, luomisesta ja ilmaisemisesta. Intuitio on Bergsonin mukaan epätarkkaa ja epäjatkuvaa; se on vain hetkellistä. Intuitio on tässä mielessä elämän sysäys itse, joka antaa ajattelulle sen kohteen, mutta vetäytyy heti taustalle. (Mt., 268.) Vaikka intuitiossa tavoitetaan Bergsonin mukaan väläys totuudesta, konkreettinen kokemus ei ole puhdasta intuitiota tai puhdasta muistamista: konkreettinen kokemus on hengen ja materian, jatkuvuuden ja eriytymisen, muistin ja havainnon risteämistä. Konkreettinen kokemus on siksi aina muuttuva, ei-yhteensattuva, eriytyvä ja ennennäkemätön.

L'évolution créatrice -teoksessa Bergson esittää myös perinteisen metafysiikan kritiikkinsä. Platon ja Aristoteles olettavat täysin muuttumattoman ja pysyvän ideaalisen totuuden, josta materiaalinen ja muuttuva todellisuus on vain heiken- 
tymää. Tämä muuttumaton totuus on Jumalan täydellistä yhteensattumista itsensä kanssa. Näin muutos, aika ja tuleminen ymmärretään vain muuttumattomuuden kautta. Vaikka moderni filosofia on toistuvasti pyrkinyt etääntymään tästä klassisesta metafysiikasta, on Bergsonin mukaan kuitenkin kyseenalaista, missä määrin se on siinä onnistunut. (Mt., 323-328.)

Eikö juuri välittömyys ole tämän Kreikasta moderniin ulottuvan metafysiikan peruskäsitteitä? Eikö välittömyys ole nimenomaan pysyvän perustan ja läpinäkyvän itsesuhteen oletus, pysyvyyden filosofian kulmakivi, jota Bergson horjuttaa jatkuvan muutoksen filosofiallaan? Tai ehkä Bergsonin välittömyyden käsitteen kautta avautuu nimenomaan jotain muuta kuin perinteisen metafysiikan määrittämä pysyvä perusta. Tässä on yksi Deleuzen Bergson-tulkinnan ydinajatuksista: välittömyydestä tulee immanenssin taso, transsendentaalinen perustattomuus, joka on "nimenomaan filosofian huimaus" (Deleuze 1968 , 164). Se on elämä puhtaana virtuaalisuutena (Deleuze 2003, 363; ks. myös Agamben 1999). Välittömyys ei siis enää olekaan välitön perusta vaan päinvastoin perustattomuuden huimaus.

Teoksessaan Les deux sources de la morale et de la religion (suom. Moraalin ja uskonnon kaksi lähdettä, 1932) Bergson ulottaa filosofiansa yhteiskunnalliselle tasolle. Hän tekee erottelun sulkeutuneen ja avoimen yhteiskunnan välillä. Sulkeutunut yhteiskunta on tiettyyn moraaliin ja normiin pysähtynyt yhteiskunta, joka sulkee ulos kaikki siitä eriävät yhteiskunnat. Tällainen yhteiskunta on nationalistinen (Bergson 1990/1932, 218) ja tekee toisesta vihollisen, joka pyritään hävittämään sodassa (mt., 227). Siinä missä täydellinen avoimuus jää tavallisen ihmisen tavoittamattomiin ja joudumme tyytymään epätäydellisyyteen, Bergson luonnehtii avointa yhteiskuntaa muuntautumiskykyiseksi (mt., 284). Kyse ei ole saman tai oman laajentamisesta vaan päinvastoin eriytymisestä ja muuntumisesta. Mutta kuten Bergson kirjoittaa, aina hetkellisesti avauduttuaan ympyrä sulkeutuu uudestaan ja konkreettisessa muutoksessa on jälleen kyse kaksoisliikkeestä ääripäiden välillä, sekä jatkuvuudesta että muutoksesta (mt., 315). Kyse on Frédéric
Wormsin mukaan "välissä olemisen politiikasta" (Worms 2012, 38) tai "puoliavoimesta" kuten Alia Al-Saji ehdottaa (Al-Saji 2019, 29), Vladimir Jankélévitchin käyttämään termiin viitaten (Jankélévitch 2008, 274).

Bergsonilla kehittyminen ei tarkoita valistuksen ajatusta historian päätepisteestä vaan päinvastoin ennustamisen mahdottomuutta, tulevaisuuden ennaltamäärittämättömyyttä ja jatkuvaa muutosta. Kyse ei myöskään ole suuresta historiallisesta tapahtumasta, joka muuttaa kaiken, vaan vääjäämättömästä muutoksesta pienimmissäkin elementeissä. Kehitys ei sulje ulos harhautumista ja vääristymistä (Bergson 1991/1907, 105). Bergson toteaa, että aika on "määrittämättömyys itse" (Bergson 1998/1934, 102). Mahdollisuus ei ole jokin vielä todellistumaton, mutta tulevaisuudessa toteutuva aktuaalisuus, vaan menneisyyteen projisoitu ja siis jo toteutunut. Toisin sanoen, tulevaisuus ei ole ennaltamäärittyneiden mahdollisuuksien toteutumista vaan "ennennäkemättömän uutuuden jatkuvaa luomista" (mt., 99). Tulevaisuus ei kuitenkaan ole vailla suhdetta menneeseen: kyse on menneisyyden muutoksesta. Bergsonin mukaan "muisti ei koostu nykyisyyden taantumisesta menneisyyteen vaan menneisyyden kehittymisestä nykyisyyteen" (Bergson 1999/1896, 269). Menneisyys on läsnä virtuaalisesti, mikä tarkoittaa, ettei menneisyys koskaan toistu sellaisenaan ja jokainen aktualisoitunut muisto on aina eriytynyt ja uusi (Bergson 1958/1919, 139).

Ei ole sattumaa, että Merleau-Ponty ja Deleuze kiinnittävät huomiota Bergsonin eriytymisen ajatukseen. Deleuzen mukaan virtuaalisuuden aktualisoituminen on eriytymistä ja elämän sysäys on kestoa, joka eriytyy itsestään (Deleuze 2004, 37). Intuitio on hänen mukaansa Bergsonilla nimenomaan metodi, joka seuraa tätä eriytymistä (Deleuze 2004, 34). Merleau-Ponty korostaa myös eriytymistä suhteessa perustavaan menneisyyteen, joka ei ole koskaan ollut läsnä (Merleau-Ponty 1999, 280; Deleuze 1993, 111-115, 136, 351), mutta toisin kuin Deleuze, hän myös kritisoi Bergsonin ajatusta välittömyydestä (MerleauPonty 1964, 165). Nykyfilosofiassa bergsonilainen jatkuvan eriytymisen ajatus on niin ikään keskeis- 
tä ja esimerkiksi Al-Saji kirjoittaa "menneisyyden uudelleenkonfiguraatiosta" (Al-Saji 2018, 341).

Bergsonille "henki" ei siis viittaa mihinkään pysyvään ideaan vaan jatkuvaan ajalliseen muutokseen. Vaikka meillä on tieteellisiä laskelmia siitä, mitä tulee tapahtumaan, yhä tarkentuvien todennäköisyyksien sarjana, emme silti voi nähdä ennalta, mitä tulee tapahtumaan. Tämä ei tietenkään tarkoita sitä, etteikö meidän olisi syytä olla huolissamme esimerkiksi ilmastonmuutoksen vaikutuksista vaan sitä, ettei elämää tule ajatella kuoleman kautta: emme koskaan saa luopua siitä mahdollisuudesta, että jotain uutta tapahtuu, jotain mikä muuttaa tapahtumien vääjäämätöntä kulkua. Toisin sanoen emme saa luopua siitä ponnistelusta, joka filosofian ja tieteen kautta luo uusia mahdollisuuksia, uusia käsitteitä, uusia keksintöjä ja uusia rakenteita, koska todellisuus itse on jatkuvaa muutosta.

Tässä Tiede \& edistyksen numerossa julkaistaan viisi Bergsonin filosofiaa käsittelevää artikkelia, jotka lähestyvät aihetta yksityiskohtaisesti. Katariina Lipsanen perehtyy artikkelissaan Bergsonin intuition käsitteeseen, joka on sivuuttamaton lähtökohta Bergsonin ajattelun ymmärtämiseen. Jan-Ivar Lindén selvittää artikkelissaan elämän käsitettä, joka tarjoaa pohjan ymmärtää Bergsonin keskeistä erottelua puhtaan muistin ja puhtaan havainnon välillä. Lauri Myllymaa puolestaan valaisee älyn ja vaiston suhdetta ja näyttää miten Bergsonilla epistemologian perusajatus kytkeytyy evoluutiobiologiaan. Julius Telivuo lähestyy artikkelissaan Deleuzen ja Bergsonin filosofioiden suhdetta naurun kautta. Katja Castillo ja Minna-Kerttu Kekki kirjoittavat toiseuden kokemuksesta suhteessa Bergsonin ajallisuuskäsitykseen.

FT JUHO HOTANEN on tutkija Jyväskylän yliopiston Yhteiskuntatieteiden ja filosofian laitoksella ja vieraileva tutkija Pennsylvania State Universityssa.

\section{VIITTEET}

1 "Élan vital" käännetään yleensä englanniksi "vital impetus" tai "vital force" ja saksaksi "Lebens-Schwung". Suomeksi Juho Hollon käännös on "elämän hyöky" (Bergson 1958/1919) ja Eetu Virenin käännös "elämän voima” (Deleuze 2018). Molemmissa suomenkielisissä käännöksissä on omat pienet ongelmansa. ”Elämän voima" jättää mahdollisuuden tulkita termiä fysiikan voimiin, esim. painovoimaan rinnasteisena vitaalisena voimana, joka näin veisi Bergsonin filosofiaa ongelmallisesti perinteisen vitalismin suuntaan. Kyse on pikemminkin impulssista, sysäyksestä tai sykäyksestä, josta myös tietoisuus on osallisena ja "elämän hyöky" tavoittaa tämän paremmin: "Tajunnan hyökyä, jossa elämän hyöky ilmenee, on sen yksinkertaisuuden vuoksi mahdoton analysoida" (Bergson 1958/1919, 148). "Hyöky" kuitenkin kuulostaa ehkä hieman liian aktiiviselta, aggressiiviselta ja hyökkäävältä. Ehdotan siksi uutta käännöstä "elämän sysäys": kyse on sysäyksinä tunnetusta elämästä, joka yhtäältä antaa sysäyksen ajattelulle ja tietoisuudelle ja toisaalta vetäytyy toiminnallisen ja tietoisen elämän taustalle. Kyse on siis eräänlaisesta avautumisen ja sulkeutumisen kaksinaisesta liikkeestä, katkonaisesta ja jatkuvasta rytmistä, elämän värähtelystä ja sykkeestä.

\section{KIRJALLISUUS}

Agamben, Giorgio (1999) "Absolute Immanence". Jean Khalfa (toim.), An Introduction to the Philosophy of Gilles Deleuze. Continuum, London/New York, s. 151-169.

Al-Saji, Alia (2018) "SPEP Co-Director's Address: Hesitation as Philosophical Method - Travel Bans, Colonial Duration, and the Affective Weight of the Past". The Journal of Speculative Philosophy, 32, no. 3, s. 331-359.

Al-Saji, Alia (2019) "Decolonizing Bergson: The Temporal Schema of the Open and the Closed". Pitts \& Westmoreland (toim.), Beyond Bergson: Examining Race and Colonialism Through the Writings of Henri Bergson. State University of New York Press, Albany, s. 13-35.

Arouet, François [Georges Politzerin pseudonyymi] (1929) La fin d'une parade philosophique: le bergsonisme. Les Revues, Paris.

Bergson, Henri (1958/1919) Henkinen tarmo. Suom. Juho Hollo. Werner Söderström osakeyhtiö, Porvoo.

Bergson, Henri (1982/1889) Essai sur les données immédiates de la conscience. Presses Universitaires de France, Paris. 
Bergson, Henri (1990/1932) Les deux sources de la morale et de la religion. Presses Universitaires de France, Paris.

Bergson, Henri (1991/1907) L'évolution créatrice. Presses Universitaires de France, Paris.

Bergson, Henri (1998/1934) La pensée et le mouvant. Presses Universitaires de France, Paris.

Bergson, Henri (1999/1896) Matière et mémoire. Presses Universitaires de France, Paris.

Canales, Jimena (2005) "Einstein, Bergson, and the Experiment that Failed: Intellectual Cooperation at the League of Nations". Modern League Notes, 120(5), s. 1168-1191.

Deleuze, Gilles (1968) Spinoza et le problème de l'expression. Les éditions de minuit, Paris.

Deleuze, Gilles (1993) Différence et répétition. Presses Universitaires de France, Paris.

Deleuze, Gilles (2003) Deux regimes de fous. Textes et entretiens 1975-1995. Les Éditions de Minuit, Paris.

Deleuze, Gilles (2004) L'île déserte. Textes et entretiens 19531974. Les Éditions de Minuit, Paris.

Deleuze, Gilles (2018) Bergsonismi. Suom. Eetu Viren. Tutkijaliitto, Helsinki.

Descartes, René (2002) Mietiskelyjä ensimmäisestä filosofiasta, Teokset II. Suom. Tuomo Aho. Gaudeamus, Helsinki.

Diagne, Souleymane Bachir (2011) Bergson postcolonial: L'élan vital dans la pensée de Léopold Sédar Senghor et de Mohamed Iqbal. CNRS Éditions, Paris.

Grosz, Elizabeth (2017) The Incorporeal: Ontology, Ethics, and the Limits of Materialism. Columbia University Press, New York.

Heidegger, Martin (2000) Oleminen ja aika. Suom. Reijo Kupiainen. Vastapaino, Tampere.

Jankélévitch, Vladimir (2008) Henri Bergson. Presses Universitaires de France, Paris.

Kelly, Michael (toim.) (2010) Bergson and Phenomenology. Palgrave Macmillan, New York.

Lawlor, Leonard (1998) "The end of phenomenology: Expressionism in Deleuze and Merleau-Ponty". Continental Philosophy Review, 31, s. 15-34.

Lawlor, Leonard (2003) The Challenge of Bergsonism: Phenomenology, Ontology, Ethics. Continuum, London/ New York.
Lazzarato, Maurizio (2019) Videophilosophy: The Perception of Time in Post-Fordism. Käännös Jay Hetrick. Columbia University Press, New York.

Levinas, Emmanuel (1967) En découvrant l'existence avec Husserl et Heidegger. Librairie Philosophique J. Vrin, Paris.

Levinas, Emmanuel (1996) Etiikka ja äärettömyys: Keskusteluja Philippe Nemon kanssa. Suom. Antti Pönni. Gaudeamus, Helsinki.

Levinas, Emmanuel (2010) "Kuinka ajatellaan ei-mitään?" Suom. Susanna Lindberg. Nïn \& näin, 4/2010, s. 38-39.

Massey, Heath (2015) The Origin of Time: Heidegger and Bergson. State University of New York Press, Albany.

Merleau-Ponty, Maurice (1960) Signes. Gallimard, Paris.

Merleau-Ponty, Maurice (1964) Le visible et l'invisible. Gallimard, Paris.

Merleau-Ponty, Maurice (1999) Phénoménologie de la perception. Gallimard, Paris.

Nizan, Paul (2002) Les chiens de garde. Agone, Marseille.

Olkowski, Dorothea (2021) Deleuze, Bergson, Merleau-Ponty: The Logic and Pragmatics of Creation, Affective Life, and Perception. Indiana University Press, Bloomington.

Pitts, Andrea \& Westmoreland, Mark (toim.) (2019) Beyond Bergson: Examining Race and Colonialism Through the Writings of Henri Bergson. State University of New York Press, Albany.

Riquier, Camille (2009) "La durée pure comme esquisse de la temporalité ekstatique: Heidegger, lecture de Bergson”. Servanne Jollivet \& Claude Romano (toim.), Heidegger en dialogue (1912-1930). Rencontres, affinités, confrontations. Librairie Philosophique J. Vrin, Paris, s. 31-67.

Sartre, Jean-Paul (2007) L'imagination. Presses Universitaires de France, Paris.

Wambacq, Judith (2011) "Maurice Merleau-Ponty and Gilles Deleuze as Interpreters of Henri Bergson". Anna Teresa Tymieniecka (toim.), Analecta Husserliana, Vol. CVIII, Transcendentalism Overturned. Springer, Dordrecht, s. 269-284.

Worms, Frédéric (2012) "The Closed and the Open in The Two Sources of Morality and Religion". Alexandre Lefebvre \& Melanie White (toim.), Bergson, Politics, and Religion. Duke University Press, Durham/London, s. 25-39. 